\title{
E-Learning Documentation of Historical Living Systems with 3-D Modeling Functionality
}

\author{
Athanasios D. STYLIADIS \\ Department of Information Technology, The Alexander Institute of Technology \& Education \\ ATEI, P.O. Box 141, 57400 Thessaloniki, Greece \\ e-mail: styl@it.teithe.gr
}

Received: July 2006

\begin{abstract}
The innovations and improvements in digital imaging sensors and scanners, computer modeling, haptic equipments and e-learning technology, as well as the availability of many powerful graphics PCs and workstations make haptic-based rendering methods for e-learning documentation with 3-D modeling functionality feasible. E-Learning documentation is a new term in computing, engineering and architecture, related to digital documentation with e-learning functionality, and introduced to literature for the first time within this paper. In particular, for the historical living systems (architectures, monuments, cultural heritage sites), such a methodolgy must be able to derive pictorial, geometric, spatial, topological, learning and semantic information from the target architectural object (historical living system), in such a way that it can be directly used for elearning purposes regarding the history, the architecture, the structure and the temporal (time-based) 3-D geometry of the projected historical living system. A practical project is used to demonstrate the functionality and the performance of the proposed methodology. In particular, the processing steps from image acquisition to e-learning documentation of the Aghios Achilleios basilica, twin lakes Prespes, Northern Greece, through its 3-D geometric CAAD (Computer-Aided Architectural Design) model and semantic description are presented. Also, emphasis is placed on introducing and documenting the new term e-learning documentation. Finaly, for learning purposes related to 3-D modeling accuracy evaluation, a comparison test of two image-based approaches is carried out and discussed.
\end{abstract}

Key words: e-learning documentation, digital photography, CAAD, historical living systems, monuments.

\section{Introduction}

The innovations and improvements in digital imaging sensors and scanners, off-the-shelf haptic devices, computer modeling software and the availability of many powerful graphics PCs and workstations make a method for e-learning documentation with 3-D modeling or 2-D drafting functionality feasible (Kalay, 2006). E-Learning documentation is a new term in informatics, engineering and architecture, related to digital documentation with e-learning functionality, and introduced to literature for the first time within this paper. 
The proposed term e-learning documentation is defined as a digital documentation procedure with e-learning functionality based on metric and non-metric (qualitative) data, and spatial and 3-D modeling semantic information (please see next Section).

In particular, for the historical living systems (i.e., monuments, churches, basilicas, archaeological sites, etc.), such a methodolgy must be able to derive pictorial, geometric, spatial, topological, learning and semantic information from the target architectural object (historical living system), in such a way that it can be directly used for e-learning purposes regarding the history, the architecture, the structure and the temporal (time-based) 3-D geometry of the projected historical living system.

At the heart of this methodology is an easy-to-develop, low-cost and accurate as-built 3-D model of the historical living system and, obviously, this is the case of the new digital image sensors and scanners (image- and scanner-based 3-D modeling). Therefore, a method like the proposed one must be based on solid-state sensors providing a sensorresolution comparable to traditional topographic and film-based technology (i.e., relative modeling accuracy better than $10^{-3}$; this results in $\leqslant 1 \mathrm{~cm}$ inaccuracy for $10 \mathrm{~m}$ run-length modeling).

The relative novel methodology for the digital e-learning documentation of historical living systems (in particular churches with complex geometry) is under development at the Alexander Institute of Technology \& Education (ATEI), Thessaloniki, Greece, in cooperation with the chair of Cadastral Survey at the "1 Decembrie 1918" University of Alba Iulia, Romania, and it is presented in this paper.

A practical project is used to demonstrate the functions and the performance of the proposed methodology. In particular, the processing steps - and the underlined e-learning functionality - from image acquisition to the e-learning documentation through the threedimensional geometric and semantic description of the Aghios Achilleios basilica, lakes Prespes, Northern Greece (as the target architectural object) in a 3-D CAAD model are presented. Also, emphasis is placed on introducing and documenting the new term $e$ learning documentation. Finaly, for documentation and learning purposes, a comparison of the results for images taken by a solid-state sensor camera and a film-based camera is carried out and presented (Kazakeviciute et al., 2005; Tseng et al., 2004).

Improvements and new developments in the fields of sensor technology and computer modeling allow the acquisition of digital images in video-realtime, without developing and digitizing a photographic film (Streilein, 1996; Kazakeviciute et al., 2005).

Such a system - which is well described by André Streilein from the ETH Zurich for digital photogrammetry and architectural design consists of two sub-systems: a subsystem for the digital photogrammetric station and a sub-system for the CAAD (Streilein, 1996; Streilein et al., 1992). In this domain the aim of a method for e-learning documentation is to make the photogrammetric data acquisition and processing easier and faster, to create a three-dimensional geometric and semantic object description, and to allow CAAD/multimedia data integration, haptic rendering, visualization and architectural processing in an easy and user-friendly way (Vladoiu, 2004; Weber, 2004).

Therefore, such a method must be capable to acquire imagery with sufficient resolution, process the data with a big level of automation, and pass the results to a data 
structure useful for 3-D CAAD modeling (Hirschberg et al., 1996). This can be achieved using solid-state sensors and manual, semi-automatic or automatic measurement techniques. Also, for environmental management purposes, the current status of a relative methodology for such a system is described by Dimen et al. (2005) and a relative method is being developed in a joint project of the ATEI of Thessaloniki in co-operation with the "1 Decembrie 1918" University of Alba Iulia.

With the constant progress of multimedia technology and network bandwidth, the traditional teaching environment that based on text and pictures, will be integrated with media streams, 3-D modeling, intelligent agents, virtual reality, haptic rendering and spatial objects (scienses) as described by Styliadis et al. (2006) for the GIS case, by Engeli et al. (1996) for the intelligent agents, and by Silva et al. (2002) for the insertion of 3-D architectural objects in photography. For this reason, in this paper, the proposed methodology shows and demonstrates an architecture (3-D model) that can support these new, rich in e-learning functionality, environments.

In general, the main architecture of the proposed e-learning method is image-based and belongs to the so-called IGM-VR architecture (Image, Geometry, Modeling, Virtual Reality-VR). Similar, e-learning architectures, with the 3-D virtual environment to promote learners study and to integrates the synchronous, asynchronous and co-operative learning environments, could be found in architecture and photography (Silva et al., 2002), in spatio-temporal data mining as it is introduced by Teng et al. (2005) in an excellent paper, and in scheduling trajectories purposes as very well described by Stefanakis (2006).

Many tasks require the generation of precise as-built CAAD models of an object, such as art historian studies, monument preservation and restoration, architecture and archaeology in general, town and regional planning, renovations, reverse engineering projects, data acquisition for city modeling and building information systems, etc. Especially, for projects in art historian studies and monument preservation it is essential to have a very precise and reliable foundation (e-learning functionality: 3-D model, semantic information, multimedia data) for the undergoing research about the monument on study. So, there is a demand for the surveying and documentation of the cultural heritage of the historical living systems. For example the world heritage list (www. UNESCO. org, 2007) has at the moment about 850 properties in 140 countries, but only a minority of them is sufficiently documented and for no more than 40 of them there is a digital documentation.

Renovations and reverse engineering of monuments take over an continuous growing part of the overall activities. Therefore existing plans and models have to be updated or to be generated at all. For the maintenance of existing monuments the use of monument information systems increases. This requires the acquisition of up-to-date threedimensional data of the existing monument, which requires approximately $80-90 \%$ of the work for such an information system as described by Pomaska (1996).

Most of the photogrammetric work for the reconstruction and documentation of historical livivg systems (monuments and archaeological sites) for cultural heritage purposes is still performed traditionally with analytical plotters without e-learning functionality, so and for e-learning purposes there is an empty research space to introduce more advanced 
fuzzy-based methodology as it is introduced by Dukic et al. (2005), by Dzitac et al. (2006) and by Pop et al. (2006). However, there are systems available that establish an on-line dataflow based learning environment based on digital monoscopic or stereoscopic image measurements (e.g., Elcovision 10, CDW (RolleiMetric), PhotoModeller (Eos), PHIDIAS). Also, in this field Nickerson (1996) reports on CART, a computer-assisted recording tool.

Even more, there are systems that make use of some semi-automatic or automatic image measurement techniques - with embedded learning functionality - like image matching or feature extraction (e.g., StereoView, DPA).

All of these systems are using CAAD models, but most of them only for just the visual representation of the photogrammetric generated results. Also, very interested, for elearning functionality purposes, is the proposed methodology by Forkuo et al. (2005) for laser scanning photogrammetric imagery, and the research work of Grebla et al. (2006) in distributed machine learning environments.

Recently, more and more systems come up that use any CAAD and semantic information available prior the measurement process. Such a system is the modeling-andrendering system developed at the University at Berkeley by Debevec et al. in 1996. This system uses a rough object description in order to guide a stereo matching technique for the digital reconstruction of the primary object details with relative accuracy better than $10^{-3}$.

Another similar system (a CAAD system named "NAOS"), dealing with 3-D geometry (with relative $10^{-3}$ accuracy as well) and qualitative information for CAAD documentation, was developed in 1997 at the Aristotle University of Thessaloniki, School of Surveying Engineering and at the ATEI of Thessaloniki, Greece (Styliadis, 1997).

Also, very interested is the work at the University of Helsinki from Haggren and Mattila (1997) dealing for 3-D indoor modeling development based on videography data. In particular, in this work a functional 3-D model of indoor scenes is built first and the measurements of the geometry based on video images are performed thereafter.

Finally, an interested CAAD system under development exists at the University of Delft (Frank van den Heuvel, 2003), which makes use of a priori geometric object information in the form of parameterized object models with image lines as the main type of observations.

On the other hand, e-learning is a process that needs quite amount of mental and body strength. In order to promote the e-learning efficiency, it is important to improve the learning environment and this is the case of the proposed methodology (e-learning with CAAD functionality).

Apart from traditional design, the new media streams and the 3-D CAAD based virtual reality can stimulate learner even more by reinforcing the learner's motivation, attention and mentality. Also, some systems adopt innovative information and communication technologies and the implemented similar environments also demonstrate satsfactory results. Such as VRML (Virtual Reality Modeling Language) for virtual 3-D scenes with walk-through functionality; but in haptic rendering while controlling the behaviors of the 3-D objects that enhance photorealism - such as the materials, the lights, the object scale, 
etc. - a script procedure must be written in the complicated VRML markup language. Evenmore, the VRML modeling (relative) inaccuracy is greater than $10^{-3}$ and so, this performance is not acceptable for e-learning documentation applications.

The proposed method is based on a 3-D CAAD model and the virtual learning architecture integrates haptic, innovative, communicative (synchronous and asynchronous) and co-operative characteristics. In particular, this article describes the performance and the e-learning functionality of the three-dimensional virtual reconstruction of the Aghios Achilleios basilica from high resolution still video imagery with the software environment NAOS (digital system for architectural modeling and documentation) (Styliadis, 1997). The object oriented measurements in NAOS are guided by a topologic model of the target architectural object.

The paper is structured as follows: In Section 2 (e-Learning Documentation: Term Formulation) the new term e-learning documentation is introduced and described. In Section 3 (e-Learning Documentation: Image-based CAAD Problem Formulation - Learning Requirements) an overview of the proposed e-learning documentation methodology is given. The Section 4 (The Main Streams of the Proposed e-Learning System) presents the main sub-systems outline design of the proposed e-learning methodology. The Section 5 (The Aghios Achilleios Basilica - A Case Study Project) describes, in detail, the methodology used for the e-learning documentation of the Aghios Achilleios basilica. In Section 6 (The CAAD Model of the Aghios Achilleios Basilica) the Aghios Achilleios basilica 3-D model (i.e., the 'heart' of the e-learning documentation) is presented.

Finaly, in Section 7 (Results Analysis - Modeling \& e-Learning Functionality) the results of the processing for the Aghios Achilleios basilica are presented and their elearning functionality is discussed.

\section{E-Learning Documentation: Term Formulation}

E-Learning documentation is a new term in informatics, engineering and architecture, related to digital (geometric and semantic) documentation with e-learning functionality, and introduced to literature for the first time within this paper.

In this Section, the proposed term e-learning documentation is defined as a digital documentation procedure with e-learning functionality based on archive (historic) photography, imagery, metric and non-metric (qualitative) data, and spatial 3-D modeling semantic information. At the 'heart' of the e-learning documentation is the accurate 3-D model (vector format) of the object (which could be any architecture, building, monument, etc.) or the process (environmental polution, weather forecast, water flood estimation, etc.) being described (Dimen et al., 2005). This new documentation includes both the traditional engineering (architectural) documentation (Leão et al., 2007; Nickerson, 1996) and the digital one (Styliadis, 1997).

The historical living systems are known as spatial-based artefacts, monuments and archaeological sites (Potier et al., 2000) that involve time, morphogenesis 3-D elements, processes and events that have been destroyed, exist or will occur (Styliadis et 
$a l$, 2005). Despite the fact that such living systems are too complicated, with significant 3-D geometry-based complexity, they could be profit from 3-D modeling based digital documentation procedures rich in e-learning functionality; and this is the case of the proposed e-learning documentation methodology.

The objectives of the e-learning documentation are:

- to facilitate and encourage the collaboration and the critical awareness between the design students, scientists and professionals (architects, designers, engineers and so on);

- to design virtual spaces using different representation methods and techniques for haptic rendering regarding architectures, landscapes and urban design;

- to communicate through 3-D model-based multimedia data in ways traditional CAAD, photography and video does not support;

- to support access to prior understandings regarding the 'pathology' (nature) and the characteristics of the described object or process;

- to allow ideas exchange and to support design autonomy;

- to test the efficiency of the various sub-systems involved in design and construction processes for the Architecture, Engineering and Construction (AEC) community;

- to promote self-directed reusable learning exercises which lead to a critical awareness of the learning process and the learner's empirical background.

Similarly, the pedagogical profit and outcomes of an e-learning documentation are:

- the establishment, through this documentation, of a new reality in education and design practice, whereby the accepted realism and the level of the 3-D modeling accuracy (or inaccuracy), of the object or the process, are not so necessary to communicate performative and reusable educational and design concepts (Martin et al., 2004);

- the real-time collaborative and reusable interactivity;

- the feedback (learning domain 3-D ontologies for semantic CAAD descriptions);

- the ability to develop manual, semi-automatic or automatic reusable CAAD learning tools that could support architectural, photogrammetric, art, historical or archaeological training and education.

The pedagogical strategy of the e-learning documentation is based on encouraging and facilitating the communication and ideas exchange between the personnel involved in the design and construction process (Leão et al., 2007).

Finaly, the characteristics of the proposed e-learning documentation are:

- active role;

- interaction;

- group work;

- design autonomy. 


\section{E-Learning Documentation: Image-Based CAAD Problem Formulation - Learning Requirements}

\subsection{Image-Based CAAD Problem Formulation}

The image data for digital architectural photogrammetry can be optained by any archive or historical 3-point perspective photography rich in geometric clues, or can be acquired with film-based cameras, as well as with cameras using solid-state sensors (Streilein, 1996).

Conventional film-based cameras still provide for an unsurpassed photographic resolution. For example, images with over 6.000 by 6.000 pixel would be required to match the resolution of a medium format film camera. But the difference between film-based cameras and cameras using solid-state sensors concerning the photographic resolution shrinks more and more (Streilein et al., 1992).

On the other hand the disadvantage of film-based cameras is that the film must be developed and digitized before the data is available for processing in a digital system. Whereas the image data of solid-state cameras is immediately accessible. This offers, among others, the advantage of quality control for image acquisition on the spot.

The formal data structure and the processing steps for 3-D modeling using the digital architectural photogrammetry technique are shown in Fig. 1. In this figure, the relation among the object and the photogrammetric data is presented in connection with the geometric, topologic and thematic data.

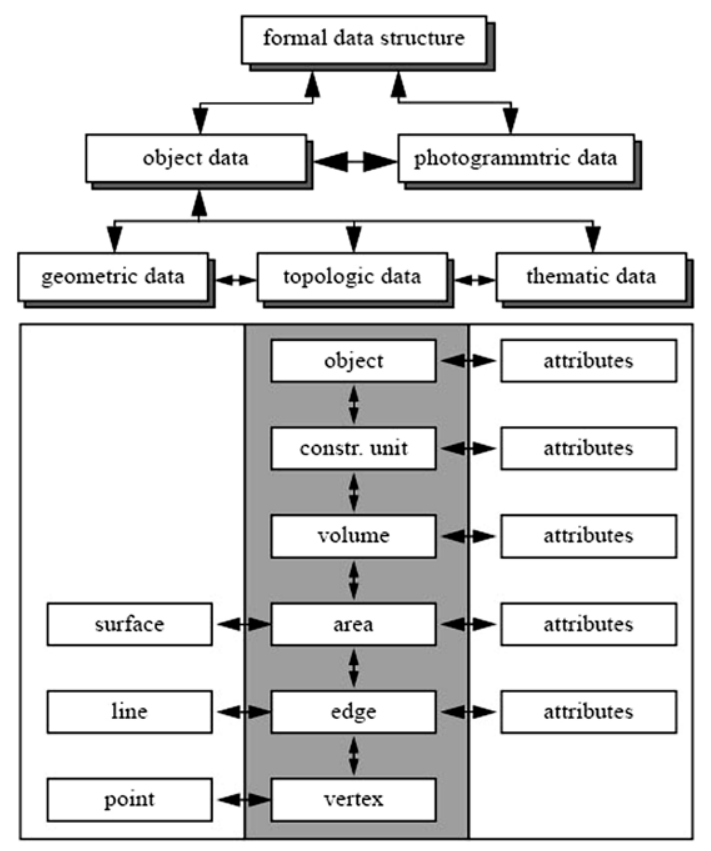

Fig. 1. The formal data structure for 3-D modeling using the digital architectural photogrammetry technique. 
Following, manual, semi-automatic or automatic measurement techniques are used for image co-ordinates measurement. Herein, the identification of architectural features and the semantic classification is performed. Then, the three-dimensional object co-ordinates are determined within a bundle adjustment (i.e., a space resection closed-form function). Finaly, the result of this modeling technique is a three-dimensional geometric and semantic description, which then can be passed to a CAAD system for further architectural processing and photorealistic enhancements.

The photogrammetric processing with a digital photogrammetric station is meaningful because of the capability using manual, semi-automatic and automatic measurement techniques. Obviously, all tasks from image acquisition to the final three-dimensional geometric and semantic object description, must be performed within the same software environment.

The major functional modules of the 3-D modeling problem formulation are: archive (historical) photography analysis, image acquisition with solid-state cameras, input and output of image data, image handling and display, manual and semi-automatic measurement techniques, radiometric and geometric image analysis, bundle adjustment (space resection) with self-calibration, model extension with semantic object information, automatic data transfer to other CAAD system, learning CAAD-objects selection and CAADobjects sequensing for an e-learning documentation course.

\subsection{Learning Requirements}

On designing the proposed methodology for the e-learning documentation, the statistical analysis results from an e-learning course in CAAD and the VRlab research project at the ATEI of Thessaloniki are examined (Tsakiris et al., 2005). So, according to students suggestion, the functional specifications for a 3-D based e-learning system are defined as follows:

- 3-D map video processing;

- 2-D image processing;

- archive or historical photography, rich in geometric regularities and properties (i.e., clues, like: planarity, parallelism, orthogonality, symmetry, perpendicularity, topology, etc.), processing (Styliadis et al., 2003);

- item-by-item 3-D modeling functionality in an e-learning CAAD environment;

- haptic rendering of the resulting virtual representations of both the 3-D maps (models) and 2-D images (drawings);

- GUI with drag-n-drop functionality;

- multimedia functionality;

- learning functionality incorporating historical and semantic data;

- force-field haptic rendering functionality;

- virtual reality functionality;

- noting- and shared-board functionality;

- non-stop study functionality.

Actually, what the learner needs is a synchronism and adaptive e-learning system which can interact in real-time with the teacher in class (Wu, 2002). In this domain an 
asynchronous system can let learner to study in his free time by adapting learning object selection (based on discrete and reusable 3-D modeling items) in intelligent learning systems (Karampiperis et al., 2004).

Also, such as system can let learners discuss with each other through media streams. Besides, they also need 3-D virtual environment with haptic rendering functionality, which can increase learner's interest and attention.

\section{The Main Streams of the Proposed E-Learning System}

After defining its functional specifications the main sub-systems (streams) of the elearning system (e-learning documentation method) are defined as follows:

- Media Stream Services: This is the server sub-system; for which a number of media stream servers are needed (e.g., a system or central server). These servers can provide data (photography, imagery, history, architecture, modeling, ets.) for learners on real-time. These servers can also store material in repository (i.e., material palettes) which then can be searched by researchers or learners (e.g., students in architecture, art, history, etc.).

- Virtual Learning Environment for 3-D Visualization: This is the client sub-system; which includes a user interface based on 3-D graphics, haptic equipment and virtual reality tools (Petrovic, 1996). It is the stage for the learner and it includes virtual and resource classroom, chat room, etc. This e-learning sub-system provides chatting functionality on a learner-to-learner or learner-to-teacher basis. After the learner's logon to the system, he can control the learning process by focusing: (i) on particular 3-D modeling and rendering methods supporting e-learning functionality, e.g., haptic rendering, phong shading rendering (Figs. 2a, 2b) or phong rendering (Figs. 3a, 3b); and (ii) on particular details of the historical living system

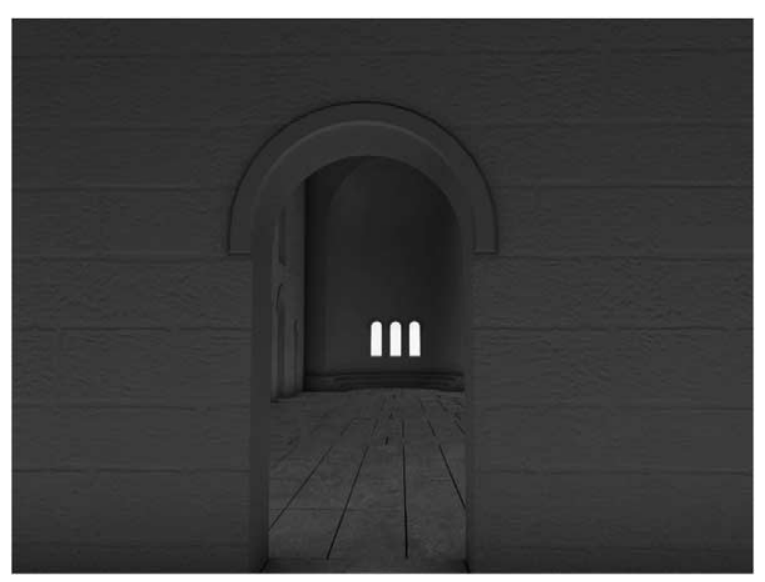

Fig. 2a. Phong shading rendering: Modeling detail of Aghios Achilleios interior, round arch \& narthex. 


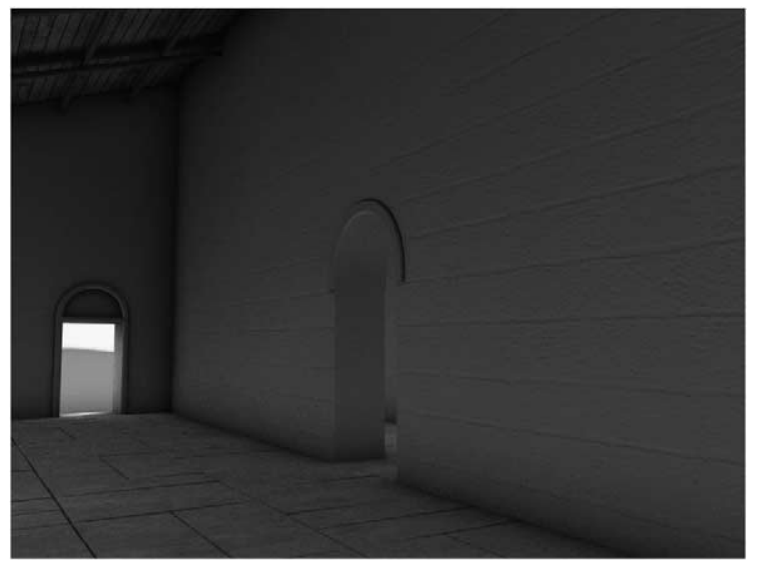

Fig. 2b. Phong shading rendering: Modeling detail of Aghios Achilleios interior, round arches \& roof.

using a GUI input device like the keyboard, the light-pen or the mouse. Evenmore, using this stream the learner can also communicate on-line with other learners (estudents).

- Web Portal: This e-learning stream provides the learner with additional information and operates as an integration platform for the entire e-learning documentation. This stream mainly includes the system's operation manual, monument's relevant documents and teaching materials, monument's architecture, history, archive (historic) photography, digital imagery, etc.

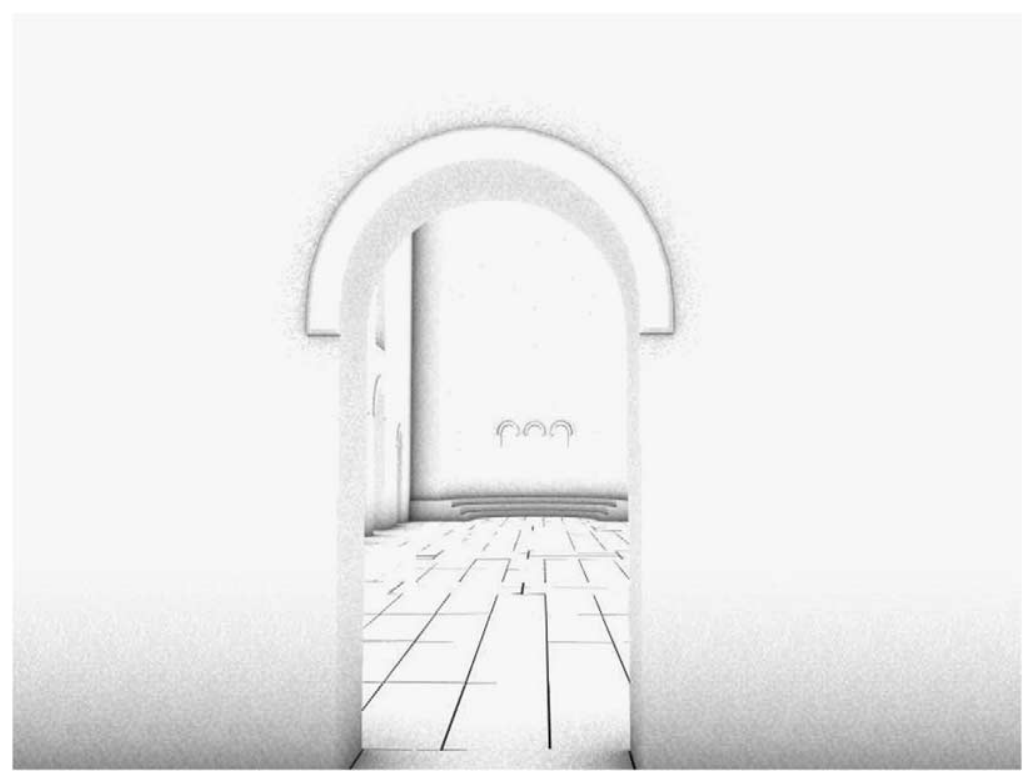

Fig. 3a. Phong rendering: A 3-D modeling detail of Aghios Achilleios basilica interior, round arch and narthex. 


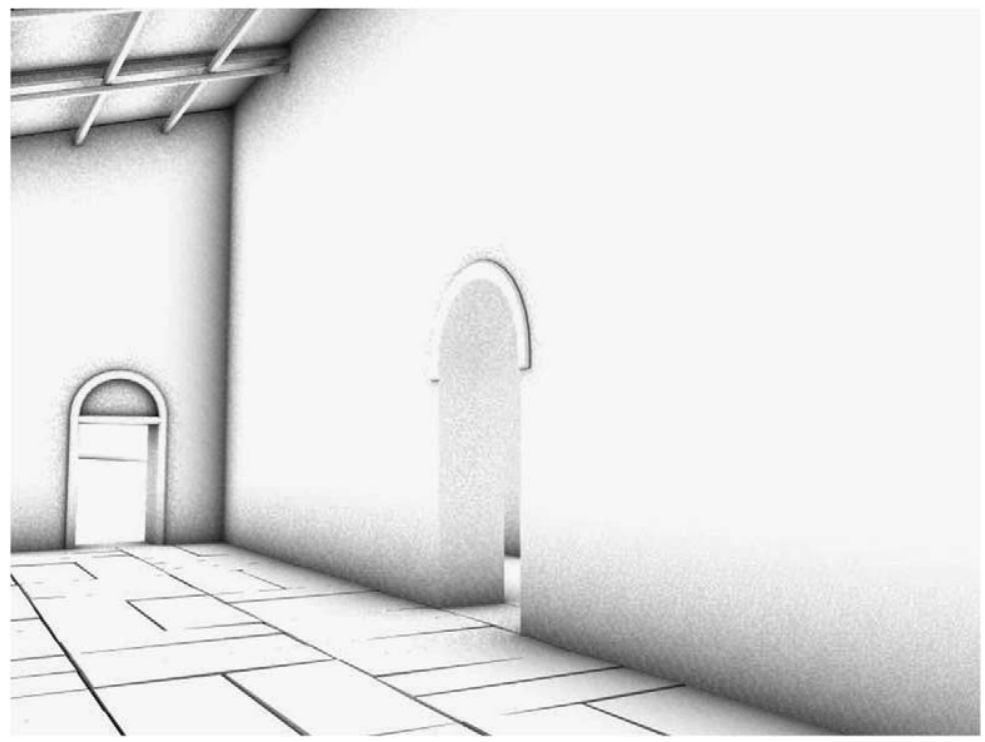

Fig. 3b. Phong rendering: A 3-D modeling detail of Aghios Achilleios basilica interior, round arches and roof.

\section{The Aghios Achilleios Basilica - A Case Study Project}

Beyond the thirsty coasts of Greece lies a lush heartland where a coachload of sunburnt tourists are a rarer sight than a flock of pink-backed pelicans. This is Macedonia, a land of legendary battles and untamed landscapes, more familiar for the news headlines it attracts than for its startling natural beauty.

Nestled, among Macedonia's verdant mountains, are the twin cool lakes of Prespa (North-West Greece). Declared as a National Park in 1974; these twin lakes provide a sanctuary for over 280 species of birds and the largest pelican breeding ground in the world. Though stranded on the edge of Greece, Prespa lies at the 'heart' of the Balkans. Straddling Greece, Albania and the Former Yugoslavian Republic of Macedonia (FYROM), these lakes are a smooth expanse of serenity caught in the crossfire of shifting borders. Locals are an unusual stew of immigrants and refugees from Pondos and Asia Minor, and nomadic Vlachs; many still speak their native dialects. But as with most of rural Greece, Prespa's population is dwindling.

At the turn of the century, there were 12,000 inhabitants and 21 villages. Now, only 1,200 locals and 12 villages are left; they survive now, as then, by fishing and farming. Until 1969, locals carried special ID cards and foreign visitors required a visa. Even today, tourism is just a slow trickle in this watery wonderland.

The Aghios Achilleios basilica, in lakes Prespes, was chosen to demonstrate the functionality and efficiency of the proposed method. Actually, the Aghios Achilleios basilica is located at the Aghios Achilleios island on the minor Prespes lake (Fig. 4). 


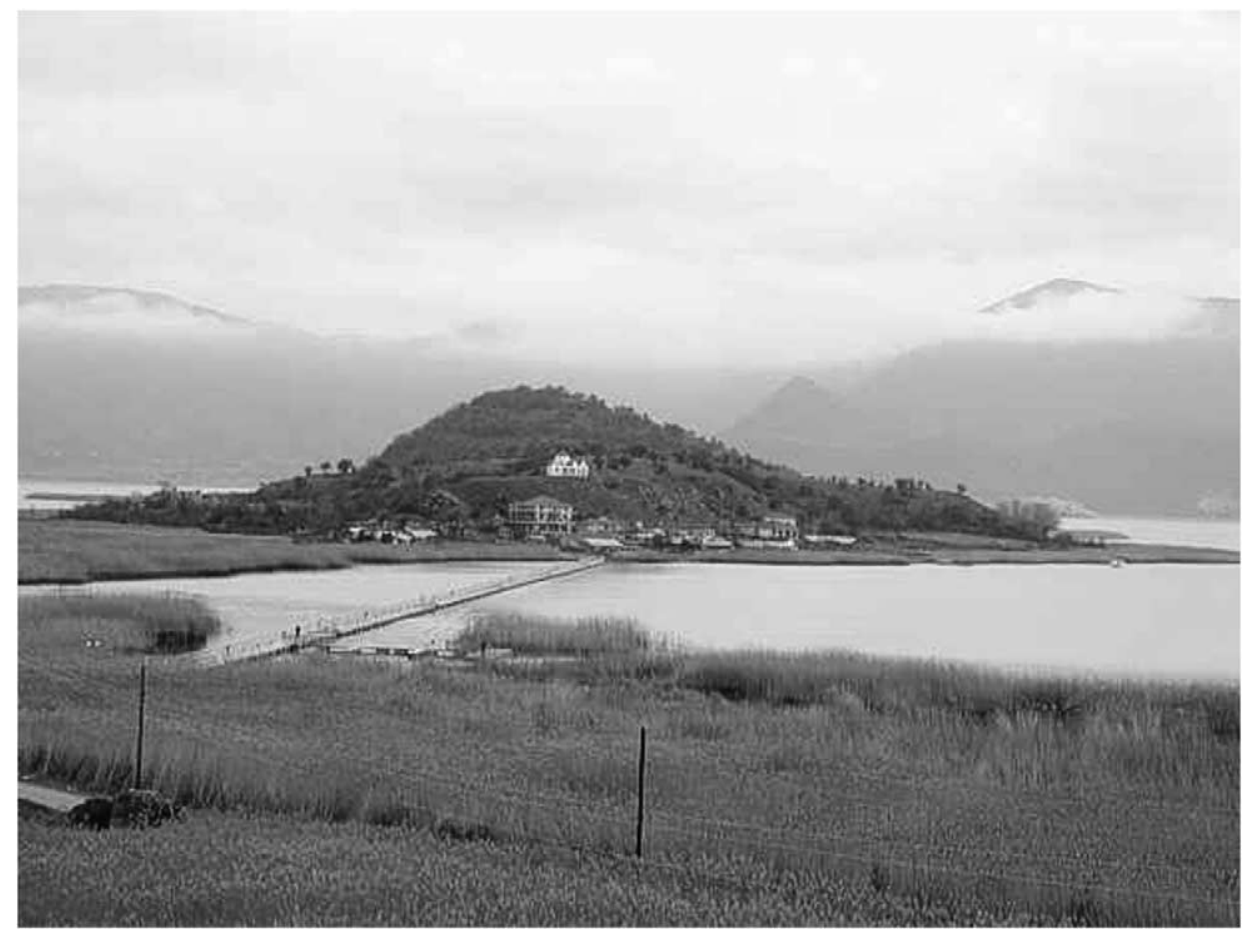

Fig. 4. The Aghios Achilleios island on the minor Prespes lake (North-West Greece).

The monument is a three-aisled, wooden-roofed basilica with a narthex and domes over the parabemata (Fig. 5). It was founded in ca. $986-990$ by tsar Samuel of Bulgaria. Initially, it was the cathedral of Samuel's short lived empire and later, until the middle of the 15th century, was an episcopal church.

A tomb covered with a relief tombstone is preserved in the south arm of the cruciform diaconicon; tradition say that the relics of Aghios Achilleios were kept in this tomb. Along the south wall of the south aisle, four other graves are preserved, in which important persons of the church or the local community were buried.

The few fragments of the wall paintings belong to two different layers and have been removed from the building (Fig. 6). They are now on display in the exhibition of Byzantine and post-Byzantine art, in the Byzantine Museum of Florina. Today, only a part of the super-structure of the building is preserved, especially on the east side.

It stands to a privileged and dominating position, nearly 20 metres above the lake of Prespes at the isle of Aghios Achilleios. The monument is about $22 \mathrm{~m}$ in length, 16 $\mathrm{m}$ in width and $6 \mathrm{~m}$ in height. A detailed discussion about the history, architectural design and construction of this basilica is given by Prof. Emeritus of Architecture Nikolaos Moutsopoulos (1999). The monument has been under restoration since 1987, and the wall masonry will be rebuilt as long as there is available evidence of its construction (Fig. 7). 


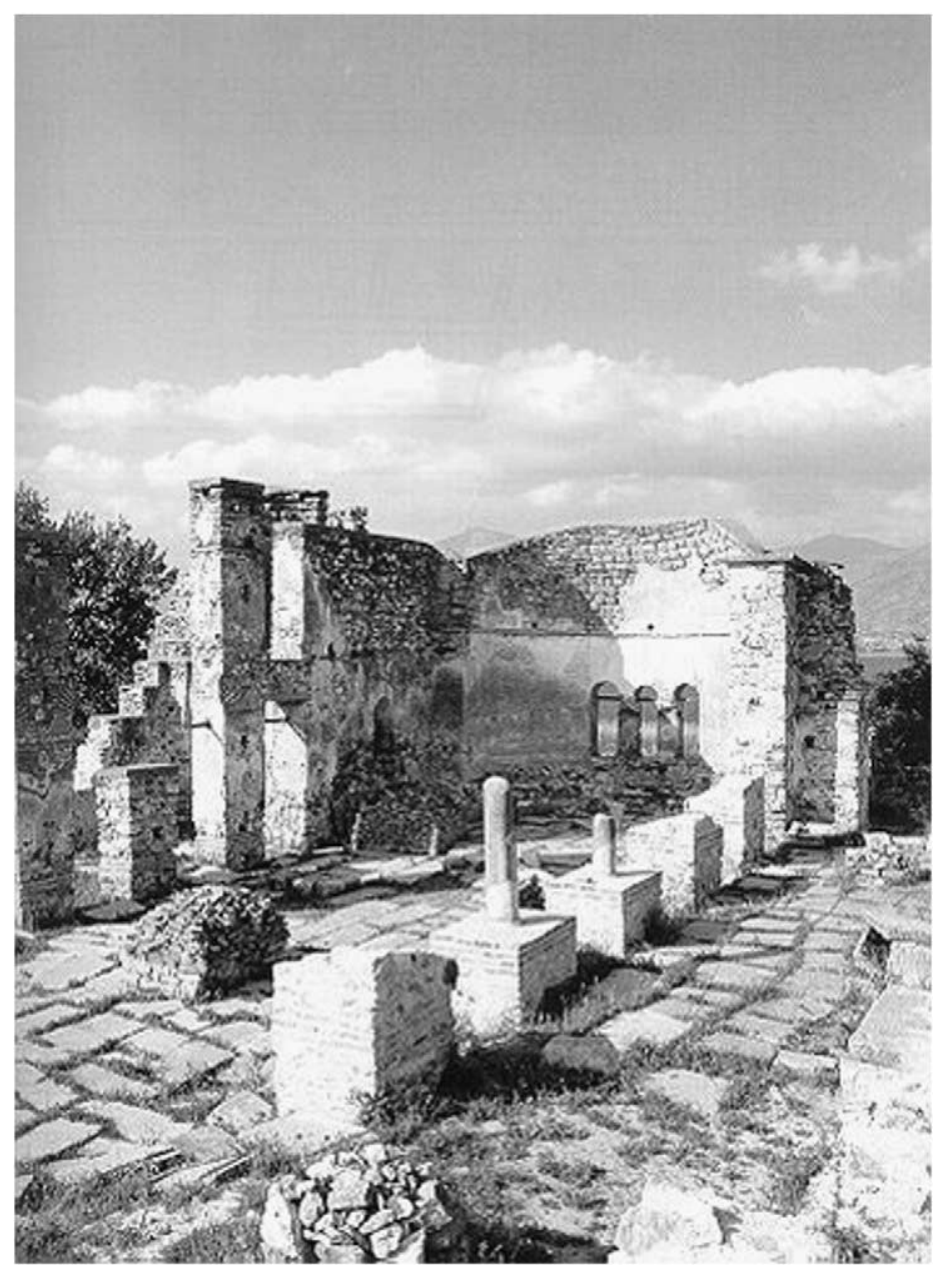

Fig. 5. The Aghios Achilleios basilica at the twin lakes Prespes.

\subsection{The Camera Shooting-Plan Arrangement}

In order to improve the efficiency of developing the 3-D geometry of the historical living system (Aghios Achilleios basilica), two plans (a detailed and a rough one) of the camera shooting stations were designed in advance (Figs. 8a, 8b). These plans are also an open case for learners of an e-learning course regarding image-based computer modeling (haptic shooting-plan arrangement).

Obviously, a well organized shooting-plan (camera stations architecture) not only save time and money but also reduce systematic complexity and 3-D modeling inaccuracy.

In general, a shooting-plan arrangment is restricted by the dimensions and the surroundings of the target architectural object.

For a haptic rendering based e-learning course, human perception combines various 


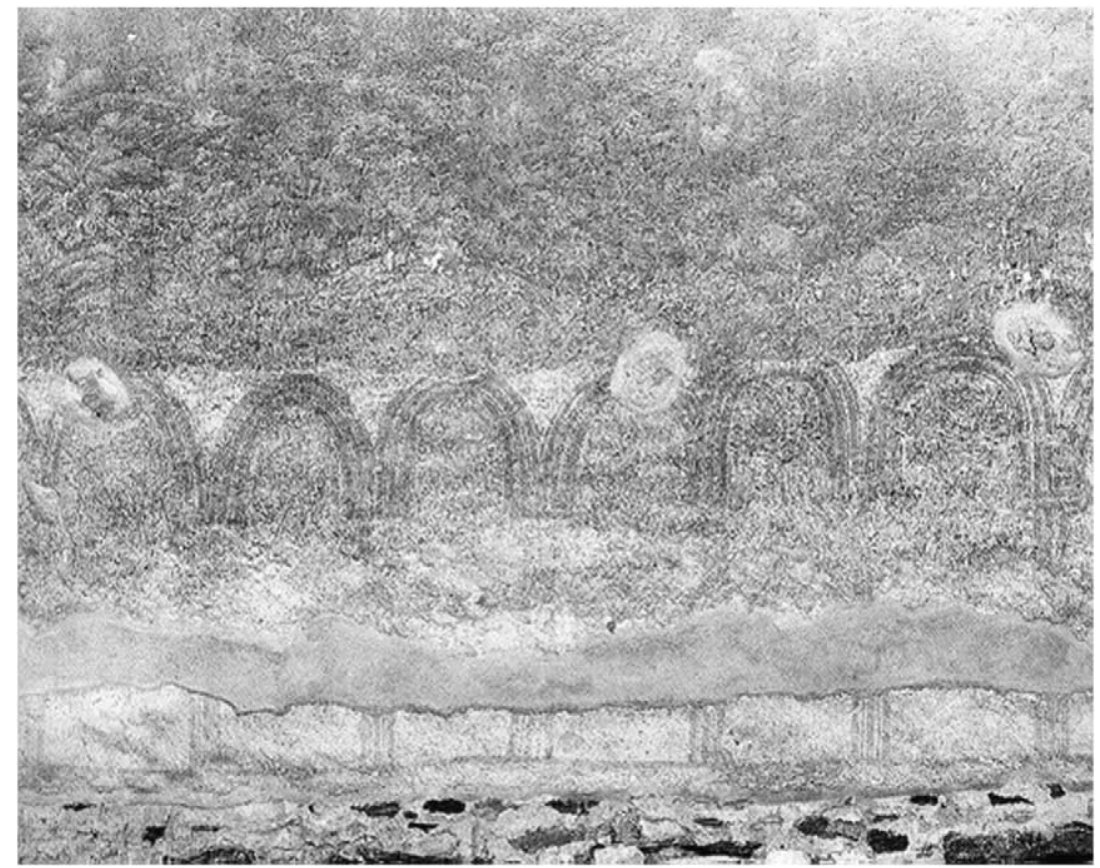

Fig. 6. The arc masonry with wall paintings of Aghios Achilleios basilica.

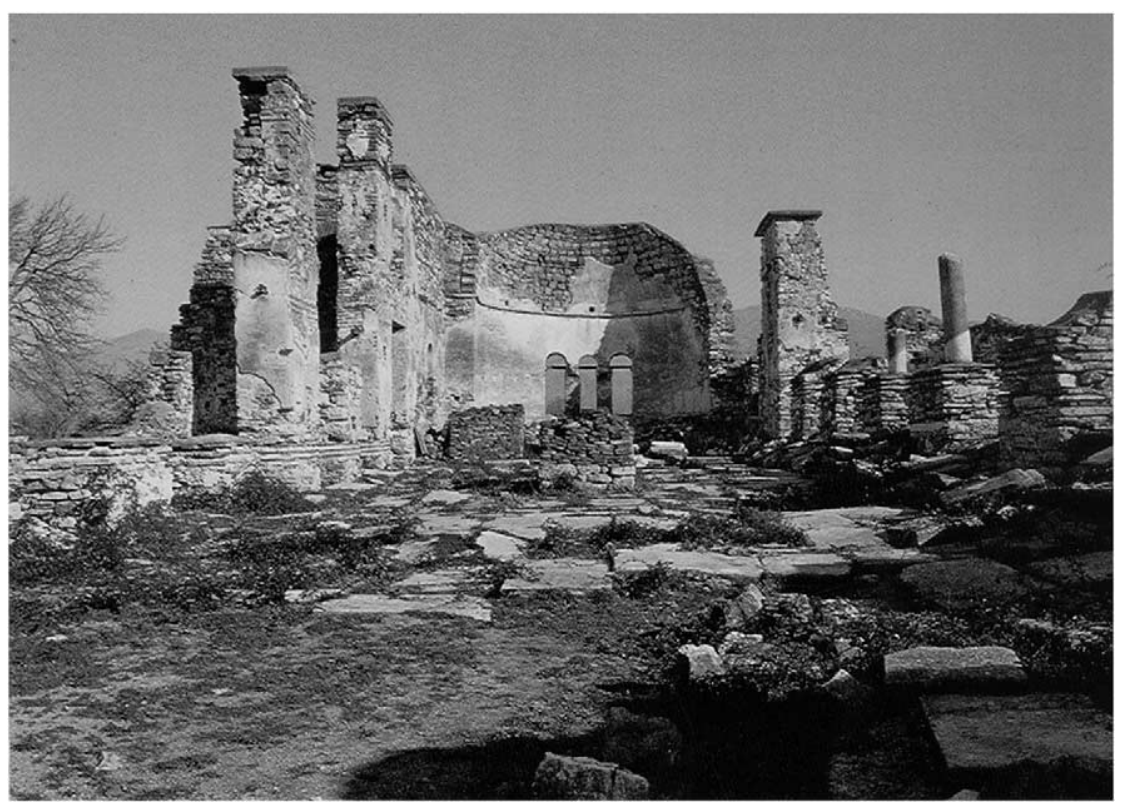

Fig. 7. The wall masonry of Aghios Achilleios basilica. 


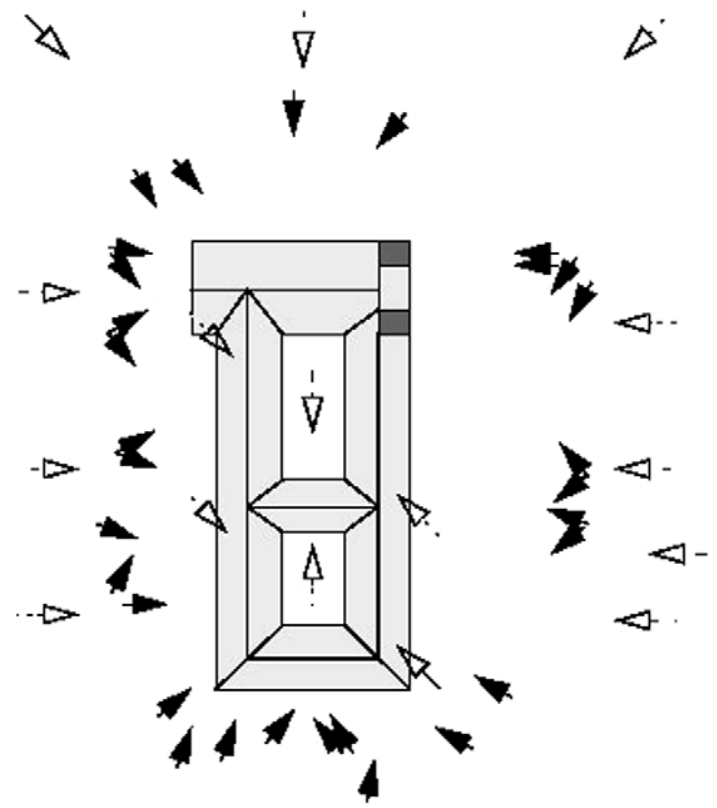

Fig. 8a. A detailed plan of the target architectural object \& the camera stations (haptic shooting-plan arrangement in an e-learning course).

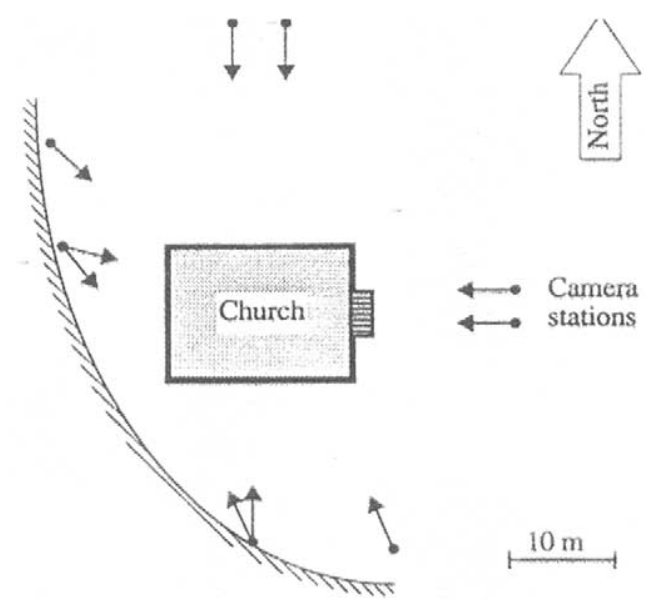

Fig. 8b. A rough plan of the target architectural object \& the camera stations (haptic shooting-plan arrangement in an e-learning course)

sensory information (ground slopes, area topography, etc.) to interpreter the environment and to arrange the camera shooting positions. In the Aghios Achilleios case, a light slope to the north and to the east of basilica's surrounding area makes an ideal camera arrangement for stereo pair shootings, for the north and east facades, possible (Fig. 8b). Also, for 
the south and west facades, just single photography was taken thanks to steep and sharp slopes in these areas (Figs. 4, $5 \& 7$ ).

\subsection{Data Acquisition (Imagery)}

The imagery of the Aghios Achilleios modeling project was acquired with a lowresolution solid-state sensor still-video digital camera (Canon CI-10) and a highresolution metric film-based analoque one (Rollei 6006).

Additionally, all the images taken with the Rollei 6006 were scanned and digitized in order to compare the results of the digital and the analogue technique under the similar resolution conditions (e-learning course educational data).

At the 'heart' of a e-learning documentation is the definition of the meta-data (primary, secondary and tertiary data) used for the digital documentation. So, for the Aghios Achilleios project the data acquisition took place during a campaign (survey) with several primary data (photography, architectural and archaeological descriptions, sketches and plans, and manual site survey measurements). From these primary data, the secondary and tertiary data were derived by different techniques, in different forms and for different purposes (e.g., cut-away and rendered views for e-learning architecture reusable educational material, spatial data and topology for reusable GIS e-learning courses, etc.).

Also, in an e-learning course one of the major purposes is the accurate spatial and modeling definition of the main structural features of the target architectural object and this is the case of stereo pair photography. Thus, in the Aghios Achilleios project the camera shooting arrangement was planned for stereo-photogrammetric tasks (Figs. 8a and $8 b)$.

This arrangement was restricted by the dimensions $(22 \mathrm{~m} \times 16 \mathrm{~m} \times 6 \mathrm{~m})$ and the surrounding of the basilica (Figs. 4, 5 and 7). In an open e-learning documentation environment, the shooting-plan arrangement could be defined virtually by the learner using haptic equipment and GUI tools (palettes, dialog boxes, etc.) with drag- $n$-drop functionality (haptic shooting-plan arrangement for the visually impaired).

\section{A) Still-Video Digital Camera (Canon CI-10)}

For the image acquisition with a camera using a solid-state sensor, the low-resolution digital Canon CI-10 colour camera with a $9 \mathrm{~mm}$ lens was used. This camera employs a CCD image sensor of $8.8 \times 6.6 \mathrm{~mm}^{2}$ with nearly 380.000 sensor elements (for red, green and blue) and recording functionality for the images on still-video floppy disks. The digitized images have a size of $508 \times 466$ pixels. This results in a pixel spacing of $15.3 \mu \mathrm{m}$ in horizontal and $12.9 \mu \mathrm{m}$ in vertical direction.

The above data are organized as e-learning course educational material and they were used in e-learning courses (for digital closed-form terrestrial and architectural photogrammetry) took place in "The 1 Decembrie 1918" University of Alba Iulia (Romania). 


\section{B) Metric Analogue Camera (Rollei 6006)}

Terrestrial cameras, like the Rollei 6006 metric one, play an important role for tasks in architectural photogrammetry. These cameras have sufficient accuracy, flexibility in handling and an ease-of-use operation.

In particular, the Rollei 6006 metric camera is an one-eye, medium format $\left(6 \times 6 \mathrm{~cm}^{2}\right)$, full automatic Motor-SLR camera system, equipped with an automatic shutter and a flash. Exchangeable magazines for roll films (12 exposures) and a selection of lenses make this camera system flexible for many applications including 3-D modeling for e-learning documentation purposes.

For the Aghios Achilleios basilica project, the images were taken with a $40 \mathrm{~mm}$ lens and a high speed colour slide film. For this metric camera the resolution depends on the scanning and digitizing procedure.

So, if the camera's colour slides will be scanned with a resolution of $8 \mu \mathrm{m}$; the resulting digital images will have a $4.000 \times 4.000$ pixel resolution! This is why these cameras are called as high-resolution ones.

The above data are organized as e-learning course educational material and they were used and tested in e-learning courses (for digital architecture, design computing and digital closed-form terrestrial and architectural photogrammetry) took place in "The 1 Decembrie 1918" University of Alba Iulia (Romania).

\section{C) Scanned Images (Rollei 6006)}

For the proposed e-learning documentation the ability of choosing the suitable photogrammetric system for the 3-D modeling is too important. So, for the comparison of the resu1ts derived (under similar conditions) with a low-resolution digital photogrammetric system (e.g., the Canon CI-10 still-video camera) and a high-resolution conventional and metric one (e.g., the Rollei 6006 metric camera), all stereo pair photography taken with the Rollei 6006 camera were scanned and digitized with the scanner Olymbus DX30.

The $6 \times 6 \mathrm{~cm}^{2}$ colour slides of the Rollei 6006 were enlarged to $24 \times 24 \mathrm{~cm}^{2}$ colour prints. This was necessary, because this Olymbus scanner accepts only opaque media. The prints were scanned with a resolution of $32 \mu \mathrm{m}$. This corresponds to scanning the slide with a $8 \mu \mathrm{m}$ resolution. So, the resulting digital images have a $4.000 \times 4.000$ pixel resolution, which is comparable to the resolution of a medium format film-based cameras.

Thereafter, using this stereo pair and the space resection procedure (Heuvel, 2003) the 3-D modeling of the basilica was constructed and it was based on the scanned images of the analoque Rollei 6006 camera.

For the 3-D modeling functionality case, the difference in resolution (and therefore in modeling quality) between the digital still-video camera and the analoque metric one, is well demonstrated in Figs. 2a, 2b (data acquisition: Canon CI-10; rendering method: phong shading) and 3a, 3b (data acquisition: Rollei 6006; rendering method: phong).

These figures show, in zoomed, a modeling and rendering detail (in a particular part of basilica's interior, round arches, narthex and roof) constructed by these two different, in 
data acquisition, techniques. The big difference of these two camera systems is noticeable and visible.

This difference in modeling quality demonstrates the need for high-resolution solidstate imaging systems for the 3-D modeling part of the proposed e-learning documentation.

\subsection{Calibration, Measurement Techniques \& E-Learning Functionality}

A e-learning documentation method for monuments and sites must offers various techniques (optios) for image co-ordinates measurement. In this case and on using a semiautomatic methods, operator's task is only to judge the scene qualitatively, whereas the quantitative statement (measurement) is done by computer. In this case, the result is not affected by the subjective human measurement.

Furthermore, the learner (operator) is supported in such a way, that all measurements and other known informations are visualized on the screen. This is comparable with the super-imposition technique used by analytical plotters. Double measurements or confusion of points are reduced to a minimum.

\subsubsection{Digital \& Metric Camera Calibration}

In order to obtain precise calibration parameters for the digital and metric cameras, used in the Aghios Achilleios basilica project, a testfield calibration was performed in advance.

So, for the digital Canon CI-10, apart from the exterior orientation six parameters $(\omega, \phi, \kappa, x, y, z)$, twelve additional calibration parameters were determined using $40 \mathrm{im}$ ages and 180 object (critical) points (Styliadis, 1997). These additiona1 parameters are: the three parameters of the interior orientation (focal length, skew angle and optical center), the scale factor (in X-, Y- and Z-direction) parameters, the X- and Y-shear parameters, and four parameters for the radial and the decentering distortion. The relative accuracy of this testfield calibration was 1:10.000.

The metric Rollei 6006 was calibrated using 30 images and 140 object (critical) points. The relative accuracy of this calibration is 1:7.000. The higher (relative) accuracy optained with the Rollei 6006 is attributable to the high redundancy of 28 rays per object point. The results of the testfield calibration were then used for the photogrammetric analysis and the modeling of the basilica.

This camera calibration procedure could be an excellent tutorial in a e-learning course about digital photogrammetry and camera calibration (e-learning documentation).

\subsubsection{Image Measurement Techniques}

For calibration, image orientation and modeling purposes the image co-ordinates of a number of signalized and architectural critical points must be determined.

For the digital Canon CI-10 case, the image co-ordinates of the signalized critical points were determined by the automatic point location technique (Streilein et al., 1992). But in some cases, due to the insufficient resolution of the images taken with the Canon 
CI-10, this measurement technique was not used. Then, it was necessary to measure these co-ordinates by the manual point location technique (Streilein et al., 1992).

The co-ordinates of the architectural critical features (points) were determined by the technique feature location via line tracking (tracked lines $\rightarrow$ extracted straight lines of features $\rightarrow$ extracted vertices of features automatically as intersections of the appropriate straight lines). Thereafter, the geometric and semantic information of the features are known. This technique delivers a precision of 1/15th (i.e., $1 \mu \mathrm{m}$ ) of the pixel spacing for the image co-ordinates of the vertices (Streilein et al., 1992).

Respectively, for the metric Rollei 6006 camera, the analogue images were measured with the analytical plotter Wild AC. A1l relevant colour slides which pictured the facades of the basilica were processed on the stages of the Wild AC for stereo measurements without exchanging the slides.

In both cases (digital Canon and metric Rollei) the signalized critical points were used to determine the orientation of the stereo pairs and then the architectural critical featurepoints were used for modeling purposes. The acquired data and the derived 3-D model co-ordinates were displayed on a PC equipped with the MicroStation CAD software, which is connected to the Wild AC (Styliadis, 1997).

Obviously, for architectural processing the photogrammetric result (3-D model coordinates) can be transformed into a standard exchange vector format (e.g., dxf) and then transferred to any vector-based CAAD software (MicroStation, AutoCAD, ArchiCAD, etc.).

For the e-learning functionality, the learner (operator) is able for haptic editing the current measurements at any stage during the 3-D modeling procedure (haptic rendering of image-based data for the visually impaired).

In the e-learning courses, the students are asked to evaluate the image measurenent techniques on the Aghios Achilleios basilica project (e-learning experiment). So, visually impaired users are asked first to organize the shooting-plan arrangement, to perform the image-based measurements, to construct the 3-D basica's model and then to navigate to the digital reconstructed basilica using a haptic device.

\section{The CAAD Model of the Aghios Achilleios Basilica}

The result of the photogrammetric processing was a 3-D geometric and semantic object description, which was passed automatically via Java-MDL programming (Java and C++ coding) to the MicroStation Masterpiece CAAD system.

This system is able to pre-process the data and store it in data structures adapted to architectural purposes; allowing, as well, data transformation into other representations in an easy way.

For the e-learning documentation, the task of the learner is the creative finding of new modeling solutions (point or parallel perspective) as well as to evaluate the current modeling accuracy, for both the point and the parallel perspective projections, in connection with the imagery processing equipment and technique used. More for 3-D reconstruction from perspective images could be found in (Yang et al., 2005). 


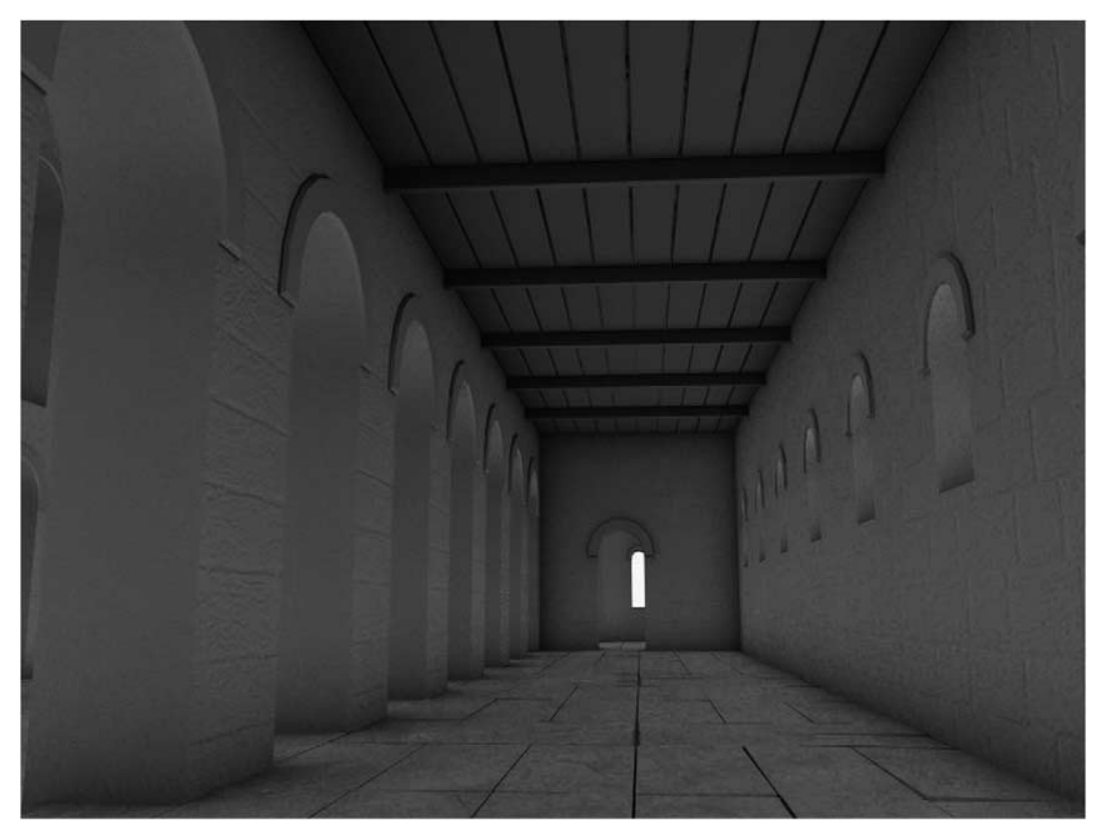

Fig. 9. Phong haptic shading rendering: A point-perspective view of the Aghios Achilleios basilica CAAD model (haptic representation based on digital low-resolution Canon CI-10 imagery).

The e-learning documentation is important for documentation and visualization purposes, and for complex simulations, manipulations and analysis of the target architectural object. This could be used in e-learning courses about architecture, archaeology and art history, in preservation of historical monuments and sites, in regional and local planning, as well as in renovations, reconstructions and reverse engineering projects.

Figs. 9, 10, 11 and 12 illustrate three point-perspective and one parallel-perspective haptic rendering perspective views of the (digital Canon-based) photogrammetric generated CAAD model of the Aghios Achilleios basilica. It is important to note that haptic interaction and rendering is especially important to e-learning students and populations with disabilities, such as the visually impaired, because tactile interpretation is one of the most important modalities they can use to perceive the world and to appreciate the monuments and the cultural heritage.

\section{Results Analysis - Modeling \& E-Learning Functionality}

For statistical and e-learning purposes the precision of the photogrammctric analysis and therefore of the resulted 3-D modeling is assessed for both, the digital Canon-based technique and the metric Rollei-based one. So, the theoretical precision of object co-ordinates was determined with a bundle adjustment (space resection). The results of this adjustment are given in Table 1. The co-ordinate system was defined with X-and Y-axis in the plane of each facade and Z-axis in depth. 


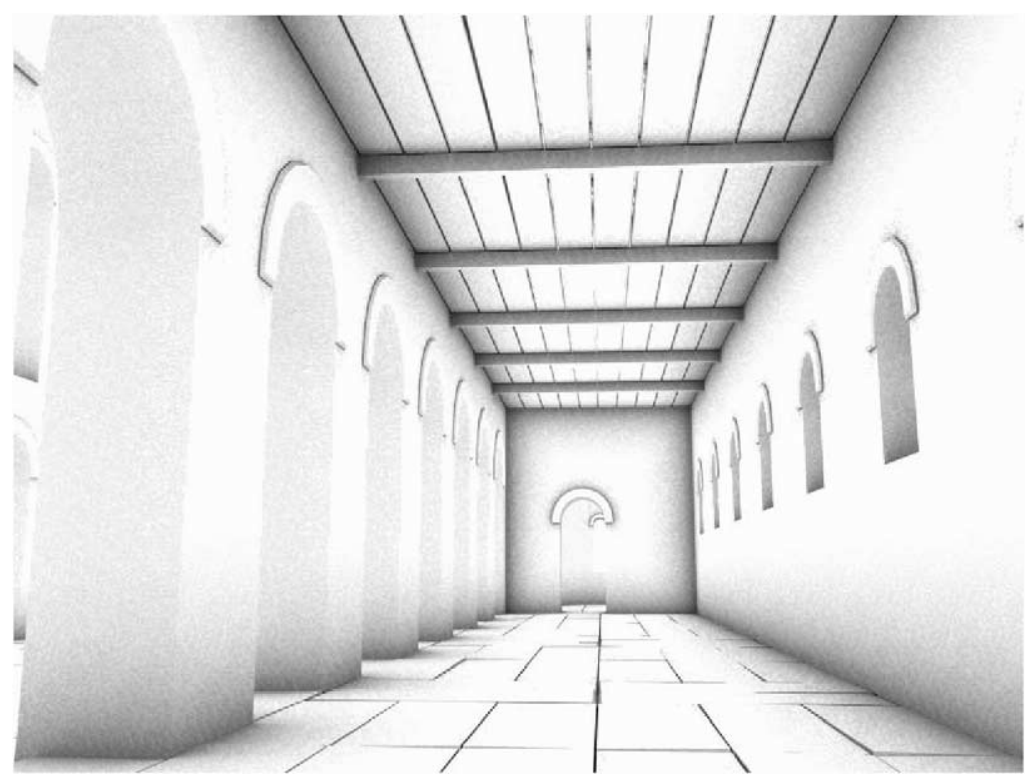

Fig. 10. Phong haptic rendering: A point-perspective view of the Aghios Achilleios basilica CAAD model (haptic representation based on digital low-resolution Canon CI-10 imagery).

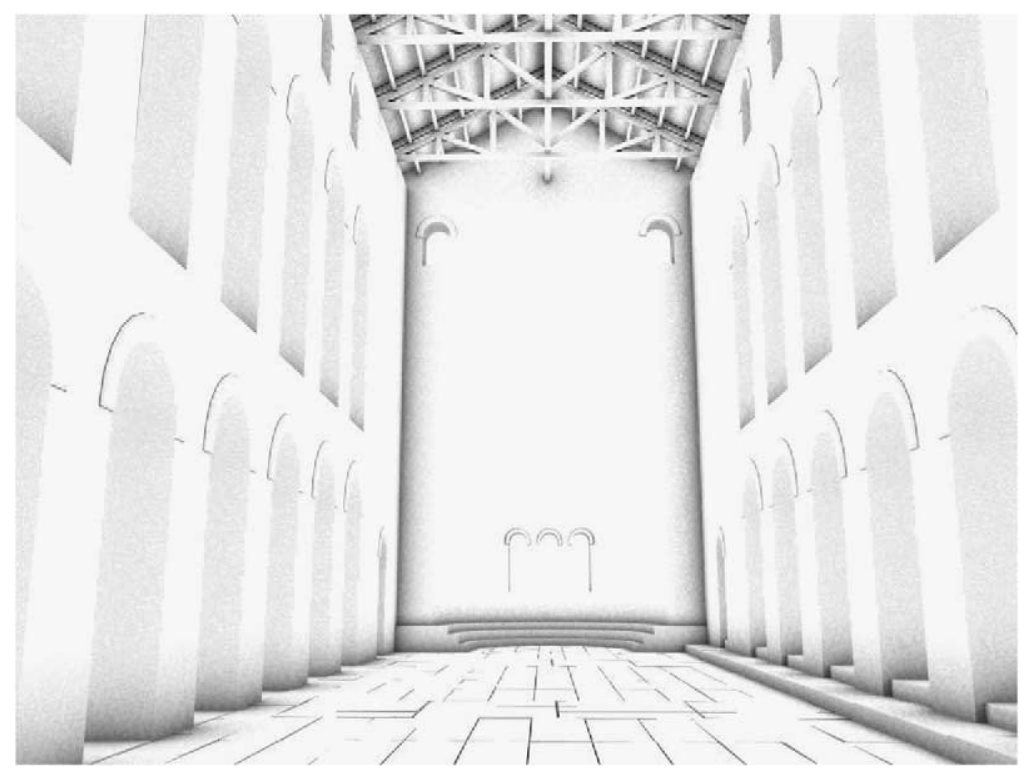

Fig. 11. Phong haptic rendering: A point-perspective view of the Aghios Achilleios basilica CAAD model (haptic representation based on digital low-resolution Canon CI-10 imagery). 




Fig. 12. Phong haptic rendering: A parallel-perspective view of the Aghios Achilleios basilica CAAD model (haptic representation based on digital low-resolution Canon CI-10 imagery).

Table 1

Statistics \& Precision of the photogrammetric analysis

\begin{tabular}{lcccc}
\hline Imaging system & No. of points & $\sigma_{\chi}[\mathrm{mm}]$ & $\sigma_{\gamma}[\mathrm{mm}]$ & $\sigma_{z}[\mathrm{~mm}]$ \\
\hline Canon CI-10 & 180 & 19 & 18 & 43 \\
Rollei 6006 & 140 & 12 & 11 & 15 \\
Digitized Images (Rollei) & 140 & 9 & 10 & 14 \\
\hline
\end{tabular}

For the digital solid-state Canon CI-10 imagery (with a number of 180 object points and 540 object point co-ordinates) the theoretical precision of the object point coordinates is about $19 \mathrm{~mm}$ (a posteriori max std. dev. X, Y) within the plane of each facade and about $43 \mathrm{~mm}$ in depth (a posteriori max std. dev. Z). This corresponds to a priori std. dev. precision of $4.7 \mu \mathrm{m}$ in image space (i.e., $33 \%$ of Canon-pixel spacing) (Styliadis, 2007).

Respectively, the metric analogue Rollei 6006 imagery (with a number of 140 object points and 420 object point co-ordinates) delivers a theoretical precision of the object point co-ordinates about $12 \mathrm{~mm}$ within the plane of each facade and about $15 \mathrm{~mm}$ in depth. This corresponds to $3.5 \mu \mathrm{m}$ in image space (30\% of Rollei-pixel spacing).

According to these results the analogue system seems to be superior, but this solely 


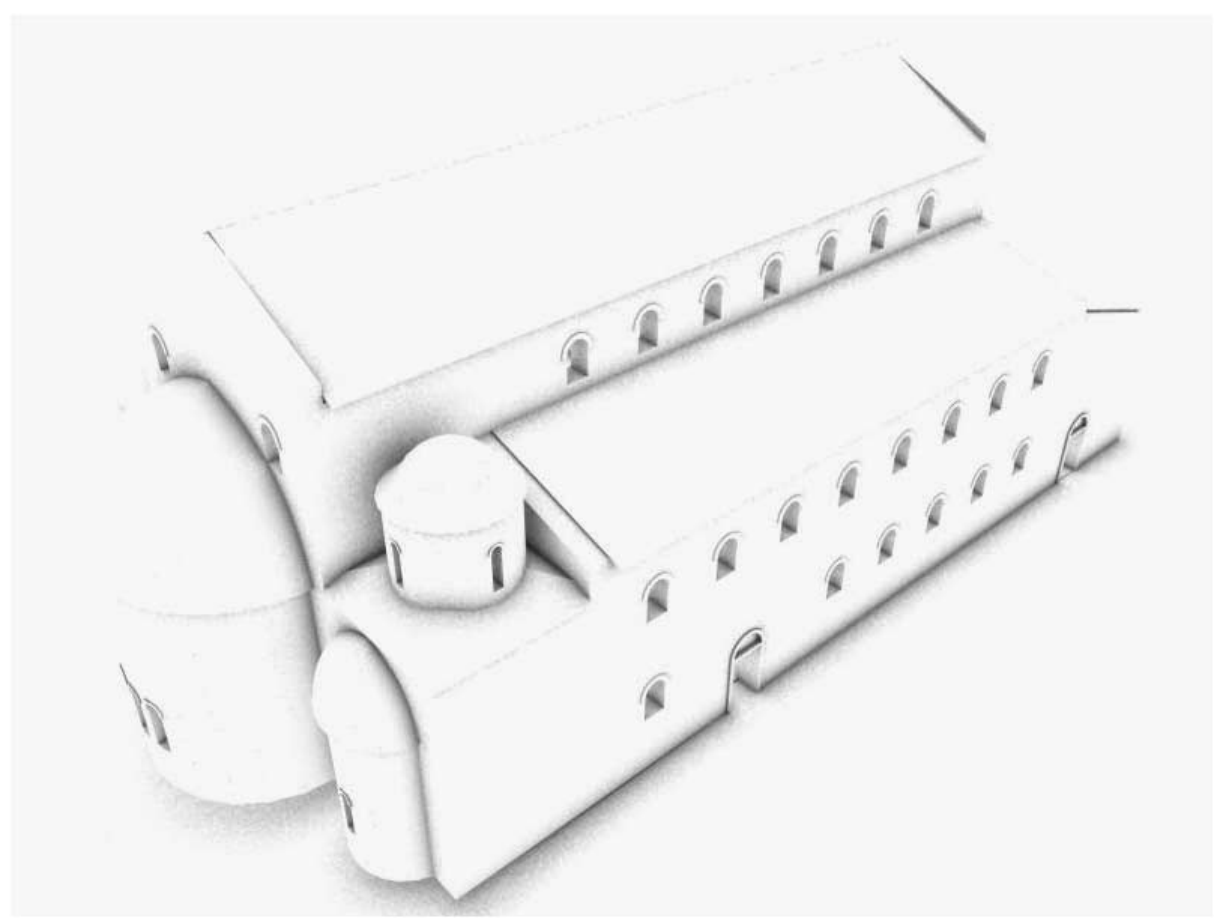

Fig. 13. An isometric phong rendering view generated with a digital technique based on Canon CI-10 imagery.

due to the much higher resolution of the analogue imaging system used (Rollei 6006). The truth is that the results of the digital system (Canon CI-10) are very encouraging when considering the low resolution of the still-video camera used.

For the 3-D modeling process in an e-learning documentation project what it makes sense, between the digital and the analogue techniques, is not only the delivering precision of the photogrammetric processing, but also the details of the target architectural object which can be measured and therefore the quality of the resulting modeling (delivering precision and modeling details). This was demonstrated in Figs. 9, 10, 11 and 12, and can also be shown in zoomed parts of the CAAD model in Figs. 2a, 2b, 3a and 3b.

Also, the following figures show isometric phong rendering views of the Aghios Achilleios basilica generated with digital Canon CI-10 images (Fig. 13), and with analogue Rollei 6006 images (Fig. 14). Finally, Fig. 15 shows a view of a radiosity based rendering model suitable for haptic rendering based e-learning applications. The primitive data (photography) for this model were acquared by the low-cost low-resolution Canon CI-10 digital camera.

For the e-learning documentation - and in order to give the learners an idea of what is to be expected from a digital imaging system providing a comparable resolution to the analogue Rollei film based one - the images (140 object points), taken with the Rollei 6006 camera, were scanned (digitized) and used. Here, the theoretical precision of the object point co-ordinates is about $9 \mathrm{~mm}$ within the plane of cach facade and about $14 \mathrm{~mm}$ 


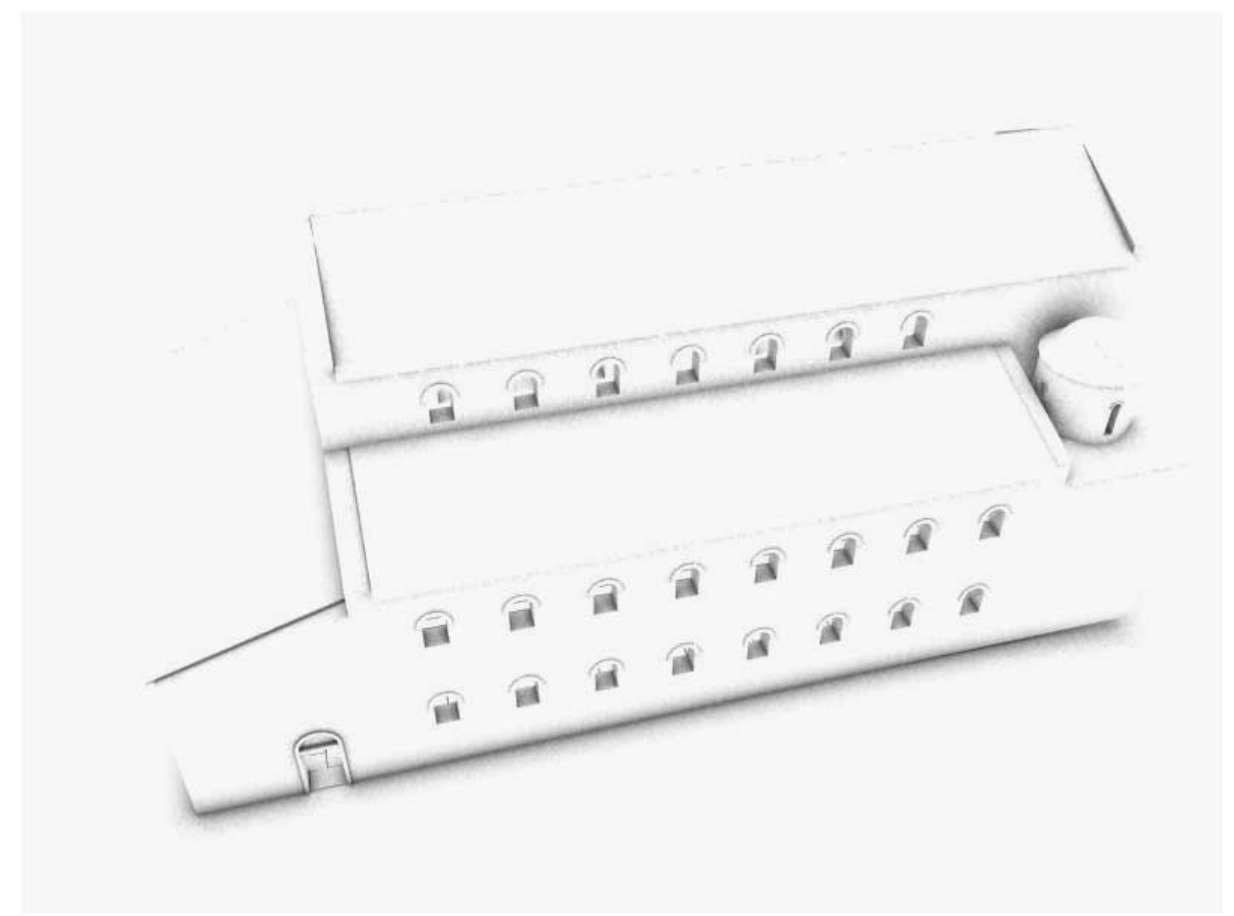

Fig. 14. An isometric phong rendering view generated with a digital technique based on Rollei 6006 imagery.

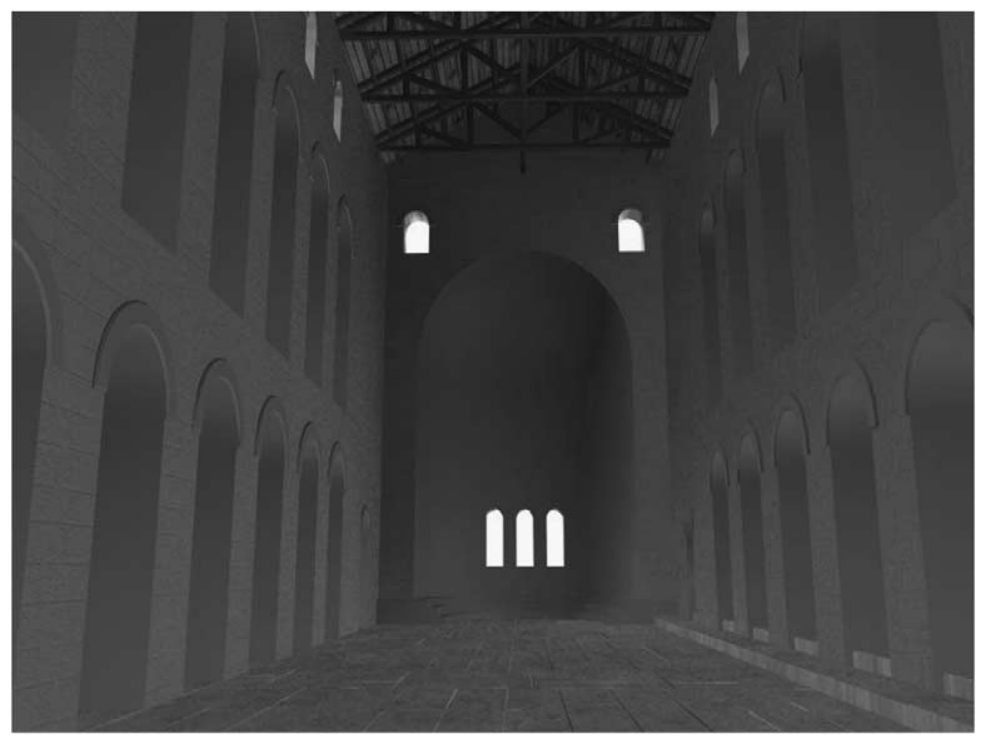

Fig. 15. An isometric radiosity rendering view generated with a digital technique based on Canon CI-10 imagery. 
in depth (Styliadis, 2007).

This is comparable (actually slightly better) to the results of the analogue Rollei filmbased technique (please see Table 1). Nevertheless, the stereo measurement mode of the analogue technique has the advantage that the geometric, construction and architectural details can be identified easier and better (and this is an interesting task in an e-learning course).

The root mean square difference of the 140 object points (located on the front, back and side facades) between analogue and digital images of the Rollei 6006 film-based camera, is $29 \mathrm{~mm}$ in X-direction, $36 \mathrm{~mm}$ in Y-direction (both in the plane of the facade) and $43 \mathrm{~mm}$ in Z-direction (depth). The really large size of this difference, as compared to the precision of object co-ordinates, is ascribed to different interpretation of the features by the operator (learner) and the digital measurement system.

Furthermore, for the e-learning documentation of the basilica, distances of the photogrammetric generated digital CAAD model were compared to the corresponding real as-built distances of the monument (the Aghios Achilleios basilica). For this purpose a number of fifty (50) distances, ranging from $0.4 \mathrm{~m}$ to $18.4 \mathrm{~m}$, were chosen. Here, the average (mean) relative distance error between the digital CAAD model of the Canon CI-IO (digital technique) and the real as-built monumental geometry is $0.60 \%$, whereas the analogue technique delivers an $0.48 \%$ average relative distance error, for the same distances. For distances over $15 \mathrm{~m}$ the average relative distance error for the low-resolution digital system was $0.32 \%$ and $0.26 \%$ for the high-resolution analogue one. For distances about $10 \mathrm{~m}$ the average relative distance error for the low-resolution digital system was $0.41 \%$ and $0.33 \%$ for the high-resolution analogue one (Styliadis, 2007).

The above statistics well demonstrate the accuracy of the digital photogrammetric processing (even with low-resolution still-video cameras) and the influence of the sensor resolutions in the final modeling accuracy (e-learning documentation).

\section{Conclusions}

In this article an overview of the current status and prospects of a method for $e$-learning documentation of historical living systems based on digital photogrammetric data (imagery) and architectural 3-D design with e-learning functionality was presented. Also, advantages and current limitations of the proposed method were discussed.

As a conclusion, conventional film-based cameras still provide for an unsurpassed photographic resolution, but the imagery must be developed and digitized before it is available in a digital system for CAAD modeling and e-learning purposes. The modeling processing with e-learning functionality is easier and faster in a digital system than in an analogue one, by using manual, semi-automatic or automatic measurement techniques. Even more, in a digital environment the processing with more than two images at a time is feasable and possible.

The e-learning documentation is controlled by additional graphical, haptic and semantic information. In this case, the current limitation is the relatively low-resolution of 
the digital imaging systems and this could cause modeling inaccuracy problems if the number of the architectural details (critical points) which can be measured is not sufficient. Obviously, this limitation and the corresponding inaccuracy demand new highresolution solid-state sensors for 3-D architectural modeling.

For the semi-automatic data transfer of the photogrammetric results to a CAAD system, a flexible three-dimensional geometric, modeling and semantic object description is given.

An interaction between the described digital documentation method and an e-learning course in architecture, archaeology, computer modeling, etc. is conceivable and desirable for the future. Furthermore, such a system could be supported by CAAD learning objects embedded into the host CAD system. These CAAD learning objects include knowledge on architectural styles, construction details of monument features, as-built details of a number of monument features, etc. Even more, in a e-learning documentation, measurement routines adapted to special characteristics of features could be manually selected by the learner (student). The features (facades, arcs, walls, etc.) already measured could be used for the digital representation of the historical living system through a CAAD software environment.

Also, this modeling process could support interactively any future measurement (dimensioning) enquire; guide learners of 3-D modeling; and support the curriculum in digital photogrammetry courses for the recognition, calibration, measurement and modeling steps through a visual process. Obviously, for all these cases a GUI dialog box for user interface support is needed as described by Petrovic (1996) in his work for design agents and creative interfaces.

Finaly, an e-learning architecture - within the 3-D virtual environment domain was proposed to promote learners study actively by integrating the synchronous, asynchronous and co-operative learning environments in order to be suitable for the many different learners' styles. For future research, the relation between the Web collaborative engineering modeling, the new haptic rendering equipment and software, and the e-learning documentation functionality must be examined, formulated and documented.

Acknowledgments. The current paper is supported by the EPEAEK II - Archimedes research project "Personalized Learning in a Reusable Way" of the Alexander Institute of Technology \& Education (ATEI), Department of Information Technology, Thessaloniki, Greece. The EPEAEK project is co-financed by the European Union $(75 \%)$ and the Greek Ministry for Education \& Religious Affairs (25\%).

\section{References}

Debevec, P., C.J. Taylor and J. Malik (1996). Modeling and rendering architecture from photographs: a hybrid geometry- and image-based approach. In Proceedings of SIGGRAPH 1996. pp. 11-21.

Dimen, L., and I. Ienciu (2005). Environmental management plan. RevCAD Journal of Geodesy and Cadastre, 5, 271-274.

Dzitac, I., and B. Pop (2006). On choosing proper linguistic description for fractional functions in fuzzy optimization. Acta Universitatis Apulensis (Mathematics and Informatics), 12, 63-72. 
Dukic, N., and Z. Avdagic (2005). Fuzzy functional dependency and the resolution principle. Informatica, 16(1), 45-60.

Engeli, M., and D. Kurmann (1996). Spatial objects and intelligent agents in a virtual environment. Automation in Construction, 5, 141-150.

Forkuo, E.K., and B. King (2005). Automatic fusion of photogrammetric imagery and laser scanner point clouds. In International Archives of Photogrammetry and Remote Sensing, vol. XXXV, part B4. pp. 921926.

Grebla, H.A., and C.O. Cenan (2006). Distributed machine learning in a medical domain. International Journal of Computers, Communications \& Control, I(1), supll. issue: Proceedings of ICCCC 2006. The AGORA University of Oradea, Romania. pp. 245-250.

Haggren, H., and S. Mattila (1997). 3-D indoor modeling from videography. In Proceedings of SPIE, vol. 3174 (Videometrics V). pp. 14-20.

Heuvel, F. van den (2003). Automation in architectural photogrammetry (line-photogrammetry for the reconstruction from single and multiple images). PhD Thesis, NCG and the Royal Netherlands Academy of Arts and Sciences (KNAW) (Eds.), The Netherlands.

Hirschberg, U., and A. Streilein (1996). CAAD meets digital photogrammetry: modelling 'weak forms' for computer measurement. Automation in Construction, 5, 171-183.

Kalay, Y.E. (2006). The impact of information technology on design methods, products and practices. Design Studies, 27, 357-380.

Karampiperis, P., and D. Sampson (2004). Adaptive learning object selection in intelligent learning systems. Journal of Interactive Learning Research, 15(4).

Kazakeviciute, G., E. Januskevicius, R. Rosenbaum and H. Schumann (2005). Tamper-proof image watermarking, based on existing public key infrastructure. Informatica, 16(1), 75-92.

Leão Ramos Ferreira Neto, P., and M. Amaral (2007). CAAD and e-learning: a blended approach. eLearning Papers, 3, 1887-1542.

Martin, D., and I. Sommerville (2004). Patterns of cooperative interaction: ethnomethodology and design. ACM Transactions on Computer-Human Interaction, 11(1), 59-89.

Moutsopoulos, N.K. (1999). The Basilica of St. Achilleios in Lake Prespes. Paratiritis Editions, Thessaloniki (in Greek).

Nickerson, S. (1996). Report on CART, a computer assisted recording tool. Automation in Construction, 5, 161-170.

Petrovic, I.K. (1996). Computer design agents and creative interfaces. Automation in Construction, 5, 151-159.

Pomaska, G. (1996). Implementation of digital 3D-models in building surveys based on multi image photogrammetry. In International Archives of Photogrammetry and Remote Sensing, vol. XXXI, part B5. pp. 487-492.

Pop, B., and I. Dzitac (2006). Fuzzy control rules in convex optimization. Studies in Informatics and Control, 16(4), 363-366.

Potier, S., J.L. Maltret and J. Zoller (2000). Computer Graphics: assistance for archaelogical hypotheses. Automation in Construction, 9, 117-128.

Silva, B., V. Alvarez, P. Cezar, P. Carvalho and M. Gattass (2002). Insertion of three-dimensional objects in architectural photos. Journal of WSCG, 10(1)

Stefanakis, E. (2006). Scheduling trajectories on a planar surface with moving obstacles. Informatica, 17(1), 95-110.

Streilein, A. (1996). Utilization of CAD models for the object oriented measurement of industrial and architectural objects. In International Archives of Photogrammetry and Remote Sensing, vol. XXXI, part B5. pp. 548-553.

Streilein, A., H. Beyer and T. Kersten (1992). Digital photogrammetric techniques for architectural design. In International Archives of Photogrammetry and Remote Sensing, vol. XXIX, part B5. pp. 825-831.

Styliadis, A.D. (2007). Digital documentation of historical buildings with 3-d modeling functionality. Automation in Construction, 16(4), 498-510.

Styliadis, A.D., I.D. Karamitsos and D.I. Zachariou (2006). Personalized e-learning implementation - the GIS case. International Journal of Computers, Communications \& Control, I(1), 59-67.

Styliadis, A.D., and M.Gr. Vassilakopoulos (2005). A spatio-temporal geometry-based model for digital documentation of historical living systems. Information \& Management, 42, 349-359.

Styliadis, A.D., P.G. Patias and N.X. Zestas (2003). 3-D computer modeling with intra-component, geometric, quality and topological constraints. Informatica, 14(3), 375-392. 
Styliadis, A.D. (1997). Digital documentation of monuments and sites with 3-D geometry and qualitative information. PhD Thesis. Faculty of Rural \& Surveying Engineering, Aristotle University of Thessaloniki, Greece (in Greek).

Teng, L., R. Liu and N. Liu (2005). A spatio-temporal data mining method for dynamic monitoring of land use. In Proceedings of SPIE, vol. 6045 I, article No. 6045OY.

Tseng, H.-W., and C.-C. Chang (2004). High capacity data hiding in JPEG-compressed images. Informatica, 15(1), 127-142.

Tsakiris, A., I. Filippidis, N. Grammalidis, D. Tzovaras and M.G. Strintziz (2005). Remote experiment laboratories using virtual reality technologies: The VRlab project. Acta Universitatis Apulensis (Mathematics and Informatics), 11, 365-378.

Vladoiu, M.-M. (2004). Towards building an open digital library for instructional design that facilitates reflective e-instruction. Informatics in Education, 3(1), 127-140.

Weber, W. (2004). SelMa - Self-guided learning in teaching mathematics. Informatics in Education, 3(1), 141150.

Wu, H. (2002). Designing a reusable and adaptive e-learning system. MSc Thesis, University of Saskatchewan, Saskatoon.

Yang, A.Y., K.H. Huang, S. Rao, W. Hong and Y. Ma (2005). Symmetry-based 3-D reconstruction from perspective images. Computer Vision and Image Understanding, 99, 210-240.

A.D. Styliadis is an associate professor of computer graphics, at the Department of Information Technology at the Alexander Institute of Technology \& Education (ATEI), Thessaloniki, Greece. He was born in 1956 and received a Diploma in Rural and Surveying Engineering (Aristotle University of Thessaloniki, Greece, 1980), an MSc in Computer Science (Dundee University, Scotland, 1987), and a PhD in Engineering for his research in CAAD, GIS, and Computer Modeling (Aristotle University of Thessaloniki, Greece, 1997). Prof. Styliadis was a fellow research scholar at the Department of Geomatics, University of Melbourne, and at the Center for GIS and Modeling (CGISM), Australia. Also, he has been worked at the Hellenic Army Geographical Service (HAGS, Athens) for three years as GIS system analyst and programmer. He has over 50 journal and conference proceedings publications and he is the author of three books in: (i) Computer Graphics (424 p.), (ii) Human-Computer Interaction - HCI Programming (488 p.), and (iii) GIS - Spatial Reasoning \& Geomatics Engineering. Prof. Styliadis' current research interests include: digital architecture, design computing and digital documentation of historical living systems, monuments and sites.

\section{Istoriniu gyvuju sistemu su 3-D modeliavimo funkcionalumu e-mokymosi dokumentacija}

\section{Athanasios D. STYLIADIS}

Darbe nagrinejjamas istoriniu gyvuju sistemu (architektūros, monumentu, kultūros paveldo vietu) perkèlimas ị skaitmeninę terpę, naudojant vaizdinę, geometrinę, topologinę, mokymosi ir semantinę informaciją iš nagrinejjamo architektūrinio objekto taip, kad ji tiesiogiai tiktu emokymuisi. Siūlomos metodologijos funkcionalumas ir veikimas demonstruojamas praktiniu pavyzdžiu: pateikiami nuoseklūs žingsniai nuo vaizdo iki e-dokumentacijos gavimo Šiaurès Graikijos Aghios Achilleios bazilikai, sukuriant šio objekto 3-D geometrinį kompiuterinị projekto modelị ir semantinį aprašą. Ypatingas dèmesys skiriamas naujam e-mokymosi dokumentacijos terminui. Taip pat aptariamas 3-D modeliavimo tikslumo įvertinimas, lyginami du vaizdais besiremiantys metodai. 